\title{
BORGES DO CANTO, O CONQUISTADOR DAS MISSÕES.
}

\section{WALTER SPALDING}

Em consequiência dos Tratados de 1750 e de 1777 , a questão de limites, no Rio Grande do Sul, ficou completamente indecisa, não se conformando, porém, o povo sul-rio-grandense com a perda da região missioneira. Diz o Sargento-mor Domingos José Marques Fernandes em sua Descrição Corográfica, Política, Civil e Militar da Capitania do Rio Grande de São Pedro do Sul. . . escrita em 1804, e que fôra testemunha ocular dos acontecimentos, que

"na (...) indecisão de limites se achavam os povos da Capitania do Rio Grande, quando nesta se rompeu a alegre nova de que Espanha tinha declarado a Portugal guerra".

A notícia chegara, da Bahia, a 15 de junho de 1801 .

O que foi essa "Campanha de 1801", em Portugal pitorescamente denominada "das laranjas" dî-lo Belisário Pimenta (1) ao comentar duas cartas e um."Diário" da referida campanha. Foi uma "guerra" de mais ou menos um mês, pois a 10 de junho de 1801 espalhava-se a notícia oficial de ter sido assinado "o tratado de paz".

Assim, pois, quando aqui chegou a notícia da guerra a 15 de junho, já ela estava concluida na Europa. Mas, enquanto não chegasse a notícia oficial daquela conclusão com assinatura do tratado de paz, em Badajoz, o sentimento do povo rio-grandense, desde muito descontente com o resultado dos Tratados anteriores, resolveu agir.

Governava o Rio Grande do Sul o tenente-general Sebastião Xavier da Veiga Cabral da Câmara (31-5- 1780 - 5-11-1801 quando faleceu no cargo). Recebendo a notícia, resolveu, de logo, preparar as tropas para a defesa das precárias fronteiras "estabelecidas" pelo Tratado de Santo Ildefonso (1777), mas ainda não demarcadas de (1). - Belisário Pimenta. - A Campanha de 1801, in "Boletím da Biblioteca da
Universidade de Colmbra, vol. XIX, 1950". 
todo. Com êsse objetivo mandou fôrças para a fronteira do rio Jaguarão que se encontraram com as espanholas concentradas em Cêrro Largo. Em seguida, a fim de melhor garantir a região, seguiu para lá o coronel Manuel Marques de Sousa que conseguiu sem grande dificuldade, a capitulação dos espanhóis. Mas no Rio da Prata tudo se preparava para um ataque de vulto ao Rio Grande, sob o comando do Marquês de Sobre-Monte que, prestes a marchar, recebeu o aviso do Tratado de Paz, assinado em Badajoz. Mas já nessa ocasião estavam os nossos de posse da fronteira Chui-Jaguarão e de quase todo o território missioneiro, para onde marchara, a 3 de agôsto, José Borges do Canto, por um lado e por outro seguira Manuel dos Santos Pedroso, com a finalidade de reaver o território missionerio, que de direito, sempre pertenceu ao Rio Grande do Sul, tendo como fronteira natural o rio Uruguai.

Comentando a notícia da declaração de guerra de Espanha, forçada por Napoleão, a Portugal, dizia em 1804 o citado Sargento-mor Domingos José Marques Fernandes:

\footnotetext{
"Sentia o governador que lhe não chegasse carta de ofício a êste respeito; e como se capacitou que as ditas notícias eram verdadeiras, mandou que os povos portuguêses reconhecessem a nação espanhola por inimiga, fazendo afixar editais nos lugares publicos desta resolução, enquanto chegasse correio, que o obrigasse a fazer a declaração de guerra com a normalidade do estilo, como com efeito sucedeu aos 16 de agôsto daquele ano".
}

Mas já nessa ocasião do recebimento oficial da declaração de guerra, Veiga Cabral havia agido na fronteira sul, enviando gente a fim de observar o inimigo. E, enquanto isso, José Borges do Canto e Manuel dos Santos Pedroso, ambos desertores, - desertores no sentido rigoroso disciplinar do Exército, mas não para os homens do Rio Grande, conforme nos ensina José Feliciano Fernandes Pinheiro (2), - enquanto isso José Borges do Canto e Manuel dos Santos Pedroso, respectivamente com 40 e 20 aventureiros cada um, e acompanhados, ainda, de militares da estirpe de Gabriel Ribeiro de Almeida (3), marcharam sôbre as antigas Missões a 3 de agôsto, antes, portanto, da deliberação do Governador Sebastião Xavier da Veiga Cabral

(2). - Anais da Capitania de São Pedro, pág. 166 e sgts. da edição do Instituto Nacional do Livro, Rio de Janelro, 1946.

(3). - Autor de uma Memória sobre a Tomada dos Sete Povos, in Missóes Orientais e seus Antigos Dominios, por Hemetério José Veloso da Silvelra. págs. 83 e sgts. 
da Câmara. A 13 de agôsto entravam êsses homens na região já então acompanhados por grande número de indivíduos, inclusive indígenas que, pelo caminho se thes iam incorporando.

Estavam, assim, de posse de todo o território missioneiro, isto é, dos Sete Povos, quando veio a notícia do Tratado de Paz de Badajoz, mandando que tudo ficasse como estava no momento. Por esta forma foi que a região missioneira do Rio Grande do Sul entregue ao Brasil pelo Tratado de Madrid (1750) e retirado pelo de Santo Ildefonso (1777), ficou definitivamente incorporado ao território da Província de São Pedro.

Há uma Noticia dos Acontecimentos pela Presente Guerra nos Sete Povos de Missóes e Nesta Fronteira do Rio Grande de São Pedro (4) que historia, em 30 de agôsto, já terem sido tomadas aos castelhanos as Missões:

- "A memorável notícia que da fronteira do Rio Pardo chegou a esta vila (do Rio Grande), de serem tomadas aos castelhanos seis povos das Missóes, explica-se da maneira seguinte: - Do regimento de Dragões da mesma fronteira, havia desertado um soldado por nome José Francisco do Canto, natural e batizado na freguezia do mesmo Rio Pardo, onde existem seus pais, e pela notícia que tinha da presente guerra, tomou a resolução de se apresentar ao tenente-coronel do mesmo regimento e comandante daquela fronteira, de cuja deserção ficou perdoado, e pedindo ao mesmo comandante licença para sair à campanha a fazer as hostilidades que lh? fôsse possivel aos castelhanos, com efeito the foi conferida não só a referida licecnça, como também de levar em sua companhia quarenta soldados auxiliares que voluntàriamente o quisessem acompanhar, muito bem armados; e como a guerra ainda se não tinha declarado naquela fronteira, somente lhe foi proibido pelo tenente-corcnel comandante o levarem fardas por se não conhecerem po: militares, pelas suas insignias; seguiram a sua marcha, dirigida às Missões, e chegando à primeira Estância da Repartição do primeiro povo de São Miguel, capital dos Sete Povos, naquela fizeram publicar aos índios que achavam na mesma, que êles iam libertá-los do grande jugo em que sempre tinham estado debaixo do poder dos castelhanos, do que os mesmos se satisfizeram muito, e os presentearam com boa cavalhada, e mantimentos, dando-lhes também linguares que os acompanharam na sua digressão".

(4). - Ano de 1801, publicado na Revista do Instituto Histórico Brasileiro - $3 a$. série - N. $11-3^{\circ}$ trimestre de 1853 , pág. 322 . 
Continuando, faz o anônimo autor dessa Memória descrita dia a dia, o relato completo até a prisão do comandante espanhol, sua chegada a Rio Pardo, prêso, e fala na liberdade que the foi concedida pelo Governador.

$\mathrm{Na}$ data de 13 de setembro narra o anônimo autor:

- A presença do $\operatorname{Ilm}^{\circ}$ e $\operatorname{Exm}^{\circ} \mathrm{Sr}$. tenente-general governador foi enviado de Missões um furriel de cavalaria miliciana contemplado nos quarenta homens que valorosamente acompanharam o co* mandante da mesma partida, José Francisco do Canto (o autor, durante todo o transcurso de seu relato escreve José Francisco do Canto, em lugar de José Borges do Canto, talvez por causa do nome do pai do herói que era Francisco), com a conta dada pelo dito comandante dos progressos acontecidos, e das disposições feitas pelo seu prudente pensar, oferecendo ao mesmo Senhor os estandartes riquíssimos das comarcas dos mesmos povos, relações de tôdas as hostilidades, armamentos, petrechos de guerra, fazendas, mantimentos e bens, de cujo procedimento teve o mesmo Senhor grande satisfação, aprovando-lhe em tudo as sábias determinações, as quaes devem ser memoráveis por não serem praticadas por servidor de século e memória".

\section{Declara a seguir que o Governador Sebastião Xavier da Veiga Cabral da Câmara}

"o premiou quanto lhe foi possivel", "nomeando ao dito Canto capitão de uma nova companhia de cavalaria de milícias, comandante geral e restaurador dos mesmos povos de Missóes" e ao fur riel enviado "nomeou tenente das mesma companhia, e lhe mandou poder para nomear o alferes à sua satisfação, que o confirmaria, assim como também a todos os oficiais inferiores e agregasse à companhia os soldados que muito bem lhe parecesse".

E, apesar da paz já de há muito firmada na Europa, ainda no Rio Grande do Sul e no Prata a luta continuava. Ainda a 12 de outubro solicitava Cabral da Câmara por empréstimo aos comerciantes do Rio Grande a quantia de oito mil cruzados

"para as tropas acampadas nas margens do rio Jaguarão, e no têrmo de quatro horas se fêz a entrega da mencionada quantia",

que foi levada ao acampamento de Jaguarão pelo sargento-mor de cavalaria ligeira, Vasco Pinto Bandeira. A 23 de outubro recebia o Governador a notícia de ter sido tomado o último povo - São Borja,

"pelo capitão de cavalaria e restaurador das mesmas, José Francisco do Canto".

Finalmente, a 31 de outubro chegava a notícia da paz: - 


\begin{abstract}
"Entrou nêste pôrto uma sumaca de Pernambuco com a notícia de estar feita a paz com Castela, e que em Lisboa se publicara a 20 de julho do corrente ano".
\end{abstract}

José Borges do Canto nasceu no Rio Pardo, tendo sido batizado a 17 de fevereiro de 1775. Era filho de Francisco do Canto e sua espôsa, D. Eugênia Francisca. O registro de batismo reza (5):

- "JOSÉ - Aos dezessete dias do mês de fevereiro de mil setecentos e setenta e cinco, nesta Matriz de Nossa Senhora do Rosário do Rio Pardo, Bispado do Rio de Janeiro; batizei e puz os Santos Óleos a José filho legítimo de Francisco do Canto natural da cidade e ilha de São Miguel, bispado de Angra: e de sua mulher Eugênia Francisca, natural e batizada na freguesia da Vila de São Pedro do Rio Grande do Sul, neto pela parte paterna de José Caetano e de sua mulher Eugênia Maria, e não houve mais notícias. E foram padrinhos José Bernardes de Meireles e sua mulher Josefa Maria de Aguiar, por seus procuradores que me apresentaram $\mathrm{Ma}^{-}$ nuel Inácio Bessa e Eugênia Maria todos moradores nesta freguesia e para constar fiz êste assento, que assino - o Padre José Antônio de Mesquita" -

Completando o assentamento acima, damos, a seguir o nome completo dos pais e avós: Pais: Francisco Borges do Canto e D. Eugênia Francisca de Sousa; Avós paternos: José Caetano Pereira, da ilha de São Miguel, Açores, e Maria Eugênia de Figueiredo, de Lisboa; Avós maternos: José da Costa e Inocência Francisca, ilheus moradores na vila do Rio Grande de São Pedro.

Os feitos de José Borges do Canto dariam para encher algumas centenas de páginas. Dêles, entretanto, o maior foi o da conquista das Missões que lhe valeu, do Governador Cabral da Câmara, o cognome de "Restaurador dos Sete Povos".

$\mathrm{Se}$, a respeito de seu nascimento não há dúvida ter sido no Rio Pardo, embora sòmente exista o registro de batismo sem referir a data natalícia, a respeito da morte do Herói Missioneiro os historiadores desafinam. Entretanto, existe no Arquivo Histórico do Rio Grande do Sul um ofício de José de Saldanha, datado de São Luís, 16 de agôsto de 1804, a que Aurélio Pôrto se reporta na citada obra (6), que historia, mais ou menos certa a causa da morte do capitão José Borges do Canto. Mas o documento que nos dá pormenores sôbre a morte e nos indica dia e mês, além do ano, está no Archivo General de la Nación, Montevidéo.

Aurélio Pôrto diz:

\footnotetext{
(5). - Livro 3o de Batismos do Rio Pardo (1774-1783), fôlha 12, segundo Aurélio Pôrto, in História das Missões Orientais do Uruguat. Pôrto Alegre, s|d. (6). - Pág. 291 .
} 


\begin{abstract}
"Saira, realmente, Canto com mais cem companheiros indios amigos, com licença do Comandante dr. José de Saldanha, que governava as Missões, para "vaquear". dentro dos limites considerados portuguêses. Transpondo os mesmos, invadira o território além Quaraí. E, por êste motivo, mandava o govêrno, em data de 6 de agôsto que, por exorbitar a concessão, fôsse o capitão Canto recolhido prêso ao quartel do Rio Pardo, juntamente "com todos os sujeitos que se achassem como êle compreendidos na queixa dos espanhóis. Ao mesmo tempo mandava-se abrir a respectiva devassa".
\end{abstract}

Entretanto, já por essa ocasião Borges do Canto estava morto. Aurélio Pôrto, transcrevendo parte do ofício do dr. José de Saldanha, comunicando o acontecido, assim historia a prisão e morte de Borges do Canto:

- "Surpreendidos por uma patrulha de fôrças do comando do ten.cel. cspanhol D. Roque Moira, o capitão José Borges do Canto, que estava nas imediações dos Arapeís, foi com seus companheiros prêso, sem poder opôr resistência de qualquer espécie, pelo descuido com que estavam entregues aos trabalhos da vacaria. Cinco dias depois, marchando custodiados pela fôrça, procuraram fugir, à noite, para um pequeno capão, mas foram novamente sapturados, com exceção de dois homens que, ocultando-se em ocos de paus, conseguiram atingir São Luis, levando ao governador a notícia dêsses sucessos".

O referido governador das Missões, dr. José de Sandanha procurou libertá-los, mas em vão, mesmo por que, quando recebeu a notícia já o "Restaurador das Missões" estava morto. E termina Aurélio Pôrto dizendo que o fato se dera "em princípios de julho de 1804".

A narrativa dos antecedentes, conforme a historia Aurélio Pôrto baseado em Saldanha, está mais ou menos certa. Mais ou menos por que, na realidade, Borges do Canto fôra "vaquear", como dizia Saldanha, acompanhado apenas por um grupo de indígenas, alguns portuguêses, quatro piás (meninos) e três índias naturais do povo de São Lourenço.

E', pelo menos, o que refere a "parte" do capitão de Blandengues Teodoro Abad. Diz êle, na referida "parte", datada de 29 de junho de 1804, depois de explicar que avistara

$$
\text { "una vaqueria en la costa de uno de los gafos del Cuarén", }
$$

que se puzera em ação e que no dia 22 os achara ao amanhecer, encontrando, aí,

"un troso de ganado como de dos mil o tres mil cavezas custodiado por dies y seis portugueses, veinte y un indios cuatro cricos, $y$ tres indias dos grandes y una chica naturales del pueblo de San 
Lorenzo, y dos paraguallos que componian 46 por todos, mandados por el capn de auxiliares José de Ocantos".

Vendo-se cercados pelos espanhóis e sem poderem resistir entregaram-se imediatamente. No dia seguinte, 23, Abad se retirou com sua gente e prisioneiros para o acampamento de Arerunga (abreviação que não conseguimos esclarecer mas que deve ser Arerunguá, antigo campo realengo da região e nome de um arroio afluente de um dos afluentes do Quaraí). No dia 26 (de junho de 1804)

"estando acampado en la costa del Cuaró como a las dos de la mañana haciendo la madrugada demasiado obscura causa de estar el tiempo llubioso me aviso el Cavo interino Bernardo Moreno soldado del Reg. de Dragones hacer fuga quince presos comprendido cn este numero el Cap. (a quien traia preso bajo su palabra de honor) a cuya tiempo uno de los cuatro sentinelas que tenia les tiro un tiro y lastimo a uno en un pié, proseguiendo la demás gente acia ellos".

Entretanto os fugitivos alcançaram um monte ocultando-se em seus matos. Mas Abad enviou, em seguida, a perseguí-los o ten. de blandengues de Buenos Aires, don Gabriel Hernandez com 15 homens, e mais o sargento do mesmo corpo, José Bello com igual fôrça, e ainda ao sargento da Colônia Antonio Asebal com 11 homens, cercando, por essa forma, totalmente o monte e o mato.

"al aclarar el dia fueron a salir por el puesto en que se hailava emboscado dicho ten. y reconociendo este que eran los presos les mando que se rindiesen lo que no obedecieron por lo que mandó a su tropa hiciera fuego por elebación a fin de contenerlos pero no siendo suficiente este fuego, seguieron en su comenzada huida".

Perseguidos, foi um dos fugitivos agarrado e intimado a entregarse, mas, tentando tomar a arma ao espanhol, foi morto pelas costas quando havia largado o soldado tentando nova fuga.

"Con este exemplo se rindieron los demás a asepcion de tres que no se pudieron encontrar. Luego mandé arreconoser al mucrto, y se reconcció sar el referido Capitan".

Com êste relato temos, pois, com exatidão, a data da morte de José Borges do Canto: 26 de junho de 1804, numa mata próximo an rio Cuaró, no Uruguai, onde foi sepultado:

"hice le diesen sepoltura y segui mi marcha para este destino" - Campamento de Arerun.a y Junio 29 de 1804. Teodoro Abad". 